\title{
Evaluation of regenerative processes in the pig model of intervertebral disc degeneration after transplantation of bone marrow-derived mesenchymal stem cells
}

\author{
Monika Barczewska ${ }^{1}$, Katarzyna Jezierska-Wozniak ${ }^{1}$, Aleksandra Habich ${ }^{1}$, Seweryn Lipinski ${ }^{2}$, Piotr Holak ${ }^{3}$, \\ Wojciech Maksymowicz ${ }^{1}$, Joanna Wojtkiewicz ${ }^{4}$ \\ ${ }^{1}$ Department of Neurology and Neurosurgery, Faculty of Medicine, University of Warmia and Mazury, Olsztyn, ${ }^{2}$ Department of \\ Electrical and Power Engineering, Electronics and Automatics, Faculty of Technical Sciences, University of Warmia and Mazury, \\ Olsztyn, ${ }^{3}$ Department of Surgery and Radiology, Faculty of Veterinary Medicine, University of Warmia and Mazury, Olsztyn, \\ ${ }^{4}$ Department of Pathophysiology, Faculty of Medicine, Laboratory of Regenerative Medicine, University of Warmia and Mazury, \\ Olsztyn, Poland
}

\begin{abstract}
Introduction: The pathophysiology of degenerative disc disease (DDD) is complex and not fully understood. While surgical treatment and appropriate rehabilitation offer relief of acute symptoms, there is a need to find tissue engineering strategies for intervertebral disc repair to restore healthy higher and histological structure. The purpose of this study was to estimate the survival rate of transplanted cells and their post-delivery integration level at the damage site.

Material and methods: We used an in vivo porcine model to investigate autogenic bone marrow-derived mesenchymal stem cell (BM-MSC) transplantation for intervertebral disc repair. In our experiment we used a large animal model of DDD induced by percutaneous laser light deliveries. The percutaneous approach has also been used for delivery of BM-MSCS into the intervertebral disc space.

Results: After MSC transplantation, we observed a deceleration of the degenerative process in the intervertebral disc, relative to degenerative discs without MSC transplantation.

Conclusions: By using a large animal model that mimicked the development of intervertebral degenerative disc disease, the present results are indicative of the clinical feasibility of this procedure.
\end{abstract}

Key words: disc disease, intervertebral disc regeneration, stem cells, regenerative medicine, porcine model.

\section{Introduction}

Degenerative disc disease (DDD) is one of the most frequently occurring ailments and can lead to serious morbidity and disability $[4,7]$. The disease process is thought to involve sequential events that lead to a loss of cells and the disc matrix [8]. With increasing age, the changes in disc morphology become disorganised, the annular lamellae become irregular, and collagen and elastin networks appear 
to become disrupted. These processes involve changes in nerves and blood vessels [39]. The current treatment of DDD is more symptomatic than curative. Thus, there is a need to search for a potentially reparative or regenerative treatment for DDD.

New experimental therapies aim to treat DDD at the genetic, cellular, and molecular levels. The most straightforward approach to repair a degenerated disc is the delivery of different cells into the nucleus pulposus (NP) to increase extracellular matrix (ECM) synthesis. A variety of cells have been used, including NP cells [33-35], chondrocytes [1,19], and mesenchymal stem cells (MSCs) [13,21-23,25,44,52,53]. All of these cell types have exhibited potential for slowing or repairing degeneration.

The studies of Steck et al. suggest that bone marrow-derived mesenchymal stem cells (BM-MSCs) could differentiate toward an NP-like phenotype in vitro [46]. Moreover, MSCs transplanted to degenerative discs in rabbits proliferated and differentiated into cells expressing some of the major phenotypic characteristics of nucleus pulposus cells, suggesting that these MSCs may have undergone site-dependent differentiation [43]. Mesenchymal stem cells can also differentiate into the chondrocyte-like cells present in the NP and regenerate the matrix. However, since the phenotype of NP cells has not been clearly characterised, confirmation of the differentiation from MSCs to NP cells has not been achieved $[15,16,26]$. These novel techniques are currently being investigated and have shown promise in small animal models $[3,49,50]$, but results in larger vertebrates have been ambiguous [1,21,22]. Thus, an experimental animal model that mimics the degenerative process in humans, and is reproducible and easy to implement, is crucial to establish a new therapeutic modality $[2,11,30]$. The models developed could be used in pharmacological studies or new tissue engineering interventions, such as stem cell therapy or new spinal implant testing. The animal models of intervertebral disc (IVD) degeneration are based on NP aspiration with a needle, or intra-NP injections of proteolytic enzymes [2,30]. However, these acute models probably do not reflect the complexity of the onset of IVD degeneration during natural aging, which also involves an early dehydration of the NP extracellular matrix. The advantage of modelling IVD in large animals such as pigs is that larger disc size, similar to that in humans, is related to the greater nutrient restriction present compared to small animal models. The larger disc size more closely mimics the conditions in adult human IVDs, where nutrients must travel up to $8 \mathrm{~mm}$ from the terminal end of the blood vessel to cells in the centre of the disc [6]. Despite some breakthroughs in IVD regeneration methods, many questions remain unanswered before clinical exploitation, such as the optimally effective stem cell type, the reliability and reproducibility of the transplantation method, and the fate of stem cells after misdirected delivery. Based on our previous results [5], we conducted a pilot study to model disc regeneration after autologous mesenchymal stem cell transplantation. To monitor the induced changes of the degenerated disc, as well as morphologic and histologic characteristics, MRI and histological studies were performed.

\section{Material and methods \\ Animals and surgical procedures}

The surgical procedure described previously was followed in this study [5]. Experiments were performed on female Large Polish White pigs at approximately 12 weeks old ( $30 \mathrm{~kg}, n=10)$. All animals were housed and treated in accordance with rules approved by the Ethics Committee (conforming to the Principles of Laboratory Animal Care, $\mathrm{NIH}$ publication no. 86-23, revised 1985). Prior to administration (30 min) of the main anaesthetic, the animals were pretreated with atropine sulphate (Polfa, Poland; $0.04 \mathrm{mg} / \mathrm{kg}$ body weight, s.c.) and azaperone (Stressnil, Janssen Pharmaceutica, Belgium; $2.0 \mathrm{mg} / \mathrm{kg}$ body weight, i.m.). The surgical procedure was performed under fractionated thiobarbital (Thiopenthal, Sandoz, Austria; 20 mg/kg body weight, IV) anaesthesia. After four weeks, five animals were re-anaesthetised and euthanised by an overdose of thiobarbital. The same procedure was performed eight weeks later for the follow-up group of five animals.

\section{Isolation of mesenchymal stem cells}

Mesenchymal stem cells were isolated from the bone marrow of porcine donors $(n=10,30 \mathrm{~kg})$ according to the protocol of Grisendi et al. [18]. Briefly, a phosphate-buffered saline (PBS)-diluted cell fraction of bone marrow was layered over a Ficoll density gradient (1.077 g/ml, GE Healthcare), followed by centrifugation at $400 \mathrm{G}$ at room tem- 
perature for $40 \mathrm{~min}$. Nucleated cells were collected, diluted with two volumes of PBS, centrifuged twice at $100 \mathrm{G}$ for $10 \mathrm{~min}$, and finally resuspended in culture medium. Cells were plated and expanded in a T-75 flask and grown for 14 days at $37^{\circ} \mathrm{C}$ and $5 \%$ $\mathrm{CO}_{2}$, with medium changes every three days.

\section{Intervertebral disc vaporisation procedure}

The IVD vaporisation procedure was performed as described previously [5]. Disc degeneration was induced at levels L2/L3, L3/L4, L4/L5, and L5/L6. Level L1/L2 was a non-injury control. Level L5-L6 was a non-transplantation control.

\section{Cell transplantation}

Immediately prior to transplantation, BM-MSCs were washed with PBS, harvested by trypsinisation, and suspended in HyStem hydrogel (Glycosan Biosystems) at a concentration of $1 \times 10^{6} / \mathrm{ml}$. Autogenic MSCs embedded in HyStem hydrogel were transplanted into the degeneration-induced $L 2 / L 3$, $L 3 / L 4$, and $L 4 / L 5$ discs in anaesthetised pigs. The entire cell transplantation procedure was performed as described previously [5].

\section{Magnetic resonance imaging}

Magnetic resonance imaging scans were used to assess the signal intensity and water content of the discs. A spinal surface coil was placed over the backs of the anaesthetised animals. Pigs were placed in the MRI scanner (3T MRI scanner Magnetom TRIO, Siemens) in a supine position, and the axial, coronal T2-weighted images (TE/TR $=102 / 4500, A V=1$, Res $=560 \times 560 \times 3000 \mu \mathrm{m})$ of the spine were acquired with the same coil geometry.

\section{Image processing}

T2-weighted coronal images centred at the intervertebral disc were used to manually draw regions of interest (ROIs) encompassing the entire disc area. The same ROls were selected for datasets acquired prior to injury as well as for those acquired four and eight weeks post injury. Signal intensity values were normalised using signal intensity in the control non-injured disc from the same animal. For each experimental group ROI signal intensity was reported as mean \pm SEM [28].

\section{Histological analysis}

After the animals were euthanised, discs from each group were harvested for histological studies. The whole discs with the vertebrae adjacent to the injured and non-affected segments (L1-L6) were removed and dissected. Tissue was fixed in phosphate buffered $4 \%$ paraformaldehyde followed by cryopreservation in 30\% sucrose and sectioning at a $7 \mu \mathrm{m}$ thickness (Hyrax C25, Zeiss) for histomorphometric analysis. A total of 50 discs were analysed, of which 10 constituted non-injury control, 10 non-transplantation control, and 30 discs were after cell transplantation. Sections were stained with Safranin O with fast-green counter staining [40].

Histological images were analysed qualitatively under a light microscope (Olympus BX51; Olympus) at magnifications ranging from $4 \times$ to $40 x$ to investigate changes in the NP and the AF. Two independent observers graded the results in a blinded manner. All harvested degenerated discs were compared to control discs within a single animal.

The proteoglycan content ratio of the cartilage (PCR) was approximated by the quantification of the Safranin O staining intensity (SOI) of the histological section. The intensity was evaluated in the superficial (S) and in the deep (D) zones of the cartilage by a manual delimitation at the upper margin of the D zone.

It was automatically measured as the result of the optical density calculated on a grey-scale obtained in the red component of the light crossing the section. In order to minimise the difference in the Safranin O staining between the sections, and to limit the effect of PCR variation during the experimental $O A$ in the $S$ and in $\mathrm{D}$ zones, the following ratio was then calculated: the $\mathrm{SOI}$ in the $\mathrm{S}$ zone was divided by the $\mathrm{SOI}$ in the $D$ zone. This justifies the expression of the PCR as a ratio.

\section{Statistical analysis}

All data were expressed as the mean \pm standard error. The Kruskal-Wallis test and the Mann Whitney $U$ test were used to analyse nonparametric data (histological grading) for the effect of treatment. Statistical analysis was performed using the SPSS program package.

All averaged data were tested using the Lilliefors test for normal distribution [26]. Statistical significance was set at $\alpha=0.05$ a priori. 


\section{Results}

\section{Culture of porcine bone marrow- derived mesenchymal stem cells}

After 10 to 14 days in culture, cells became relatively homogeneous and had a spindle-shaped appearance when approaching confluence. This morphology remained unchanged until the release of cells for treatment.

\section{Magnetic resonance imaging}

The analysis of signal intensity in T2-weighted transverse images of the intervertebral discs was the basis of the presentation of the evolution of the visible characteristic of the discs after the laser vaporisation only (Fig. 1B) or additional BM-MSCs injection (Fig. 1C) and control discs (Fig. 1A). After eight weeks, there was observed lower percentage (36.1\%) of progression of disc degeneration (as the lowering of T2-weighted signal intensity) in the IVDs after BM-MSC transplantation than observed in only injured IVD (46.7\% progression) (Fig. 2). Four weeks after the injury the $\mathrm{T} 2$ signal intensity index decreased in both impacted groups of IVDs (without and with BM-MSCs transplantation; Fig. 3).

\section{Histological changes}

Safranin O staining revealed many morphological changes ranging from normal to severely degenerated. Control, non-affected discs had a smooth
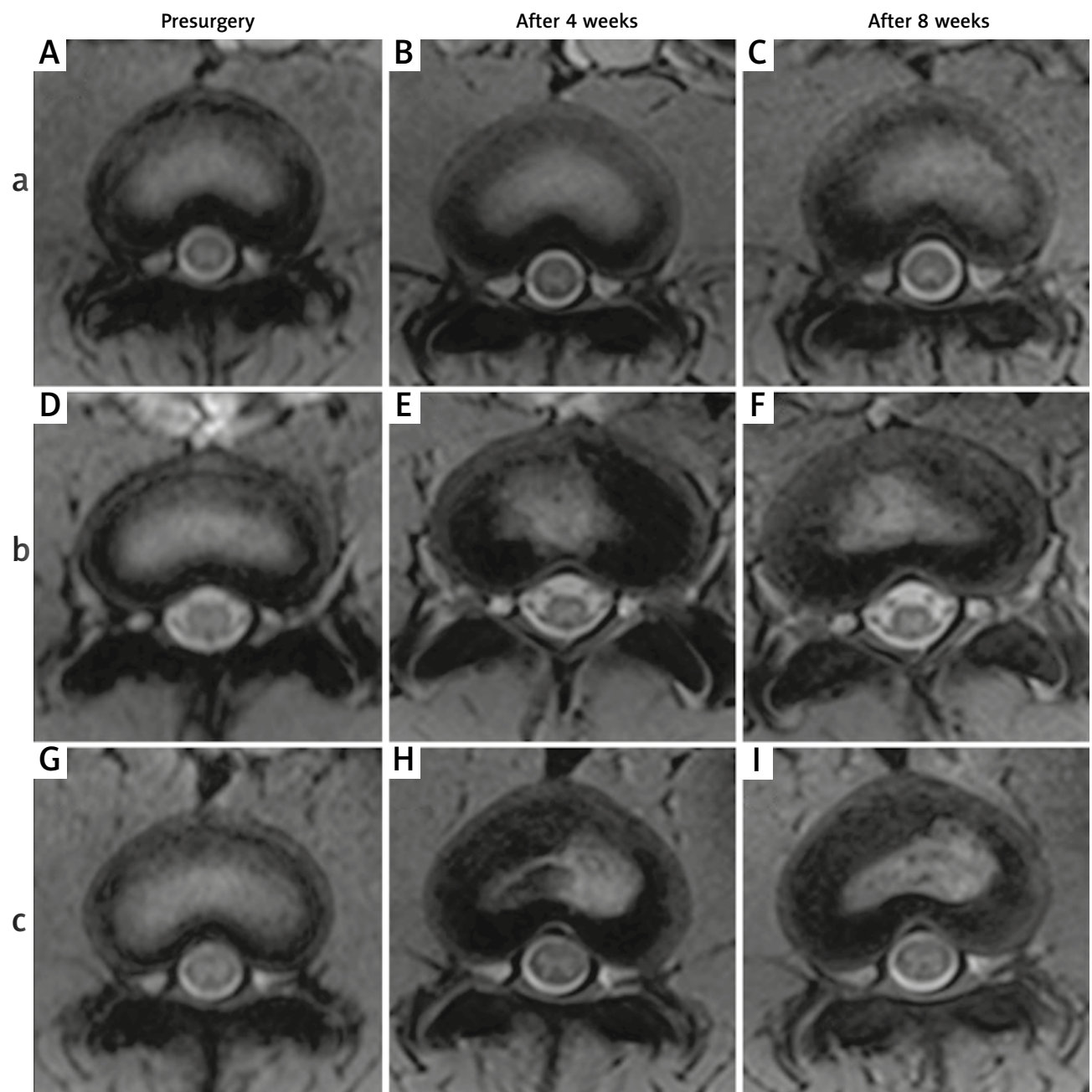

Fig. 1. Representative magnetic resonance images (T2-weighted axial). A-C) Untreated intervertebral disc (IVDs) (control) were used as an internal control. D-F) IVDs were injured without cell transplantation. G-I) IVDs injured after bone marrow-derived mesenchymal stem cells (BM-MSCs) transplantation - IVDs were injured and transplanted with BM-MSCs. 


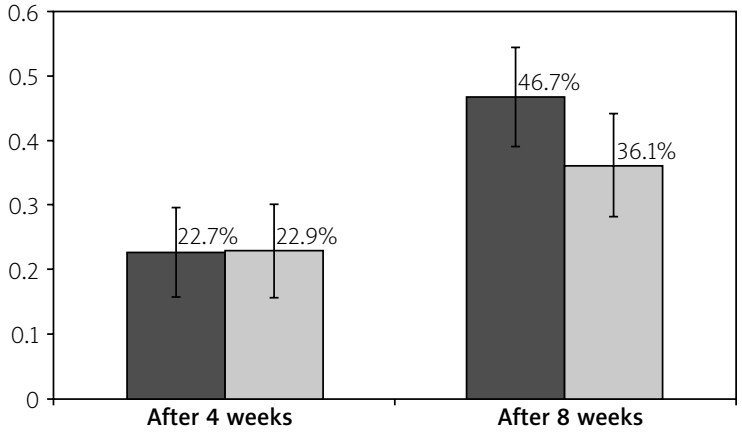

Fig. 2. Nucleus pulposus signal intensity index. T2-weighted signal intensity was measured four and eight weeks after injury. Percentage decrease in the mean T2 signal intensity of intervertebral discs was used as injured control (lines) and after bone marrow-derived mesenchymal stem cells transplantation in relation to their initial (lattice).

surface, normal structural organisation, and uniform Safranin O staining. Normal-appearing discs displayed an intact superficial zone with a normal pattern of fibrocartilage lamellas and a normal extracellular matrix architecture. The periphery of the NP was lined by a thin sheath of cell-containing matrix. The boat-shaped NP comprised at least one-half of the disc area at the midsagittal cross-section. The nucleus pulposus consisted of numerous large and vacuolated cells (Fig. 4A). In the intact discs, the inner annulus and part of the outer annulus showed similar, strong Safranin O staining. However, the stained sections were not homogeneous, as some regions were stained very intensely compared with the surroundings. The superficial annulus displayed a normal pattern of fibrocartilage lamellas shaped in the posterior aspect of the disc. In the evaporated discs, the positively Safranin O stained area of the AF, as well as in the NP, was decreased. In degenerated discs, we observed changes in the extracellular matrix (discontinuity, matrix vertical fissures into the mid zone, or matrix loss) and cell architecture (dead cells, hypertrophy, clusters). Moreover, in the mid zone, the disorientation of chondron columns and cationic stain matrix depletion could be noted (Fig. 4B). After MSC transplantation, certain tissue changes, indicative of the regeneration process, were observed. The NP and annulus fibrosus consisted of large and vacuolated cells. In the deep zone of the annulus fibrosus, an increase in the cationic stain was observed (Fig. 4C).

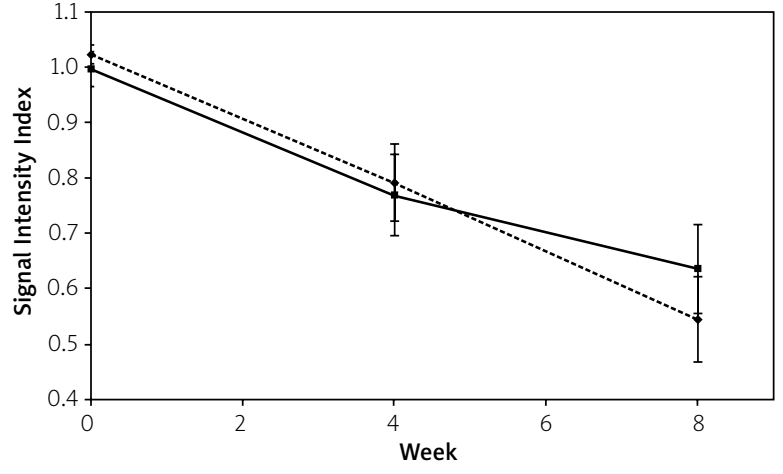

Fig. 3. T2 signal intensity index (mean \pm SEM) of intervertebral discs used as an injured control (dashed line) and after mesenchymal stem cells transplantation (solid line).

\section{Proteoglycan content ratio}

The proteoglycan content was evaluated by measuring the SOI in the superficial and the deep layers of the intervertebral disc cartilage. The SOI in the affected discs after MSC transplantation tended to be higher compared to controls; however, the differences were not significant.

\section{Discussion}

Mesenchymal stem cells have been recognised as the most likely candidate for in vivo NP repair. The use of MSCs in the present study was appropriate because these cells have the ability to undergo multilineage differentiation, and are also highly viable in vitro. Previous results from in vitro and animal studies indicated that using expanded bone marrow MSCs to treat degenerative disc disease may be effective [37-39,42,43]. Bone marrowderived MSCs have been injected into the intervertebral discs of rabbits [42-44], rats [13], dogs [21], and goats [55] and have demonstrated meaningful regenerative potential. This may be due to the fact that after introducing MSCs into the damaged and hypoxic environment of the NP, MSCs differentiate into chondrocyte-like cells native to the NP, both ex vivo and in vivo $[10,14,38,42,45]$, or to their trophic effect on NP cells by increasing viability [51] or, for example, by increasing collagen type II gene expression [50]. Favourable data have also been reported with MSC transplantation in human discs $[24,35,54]$. 

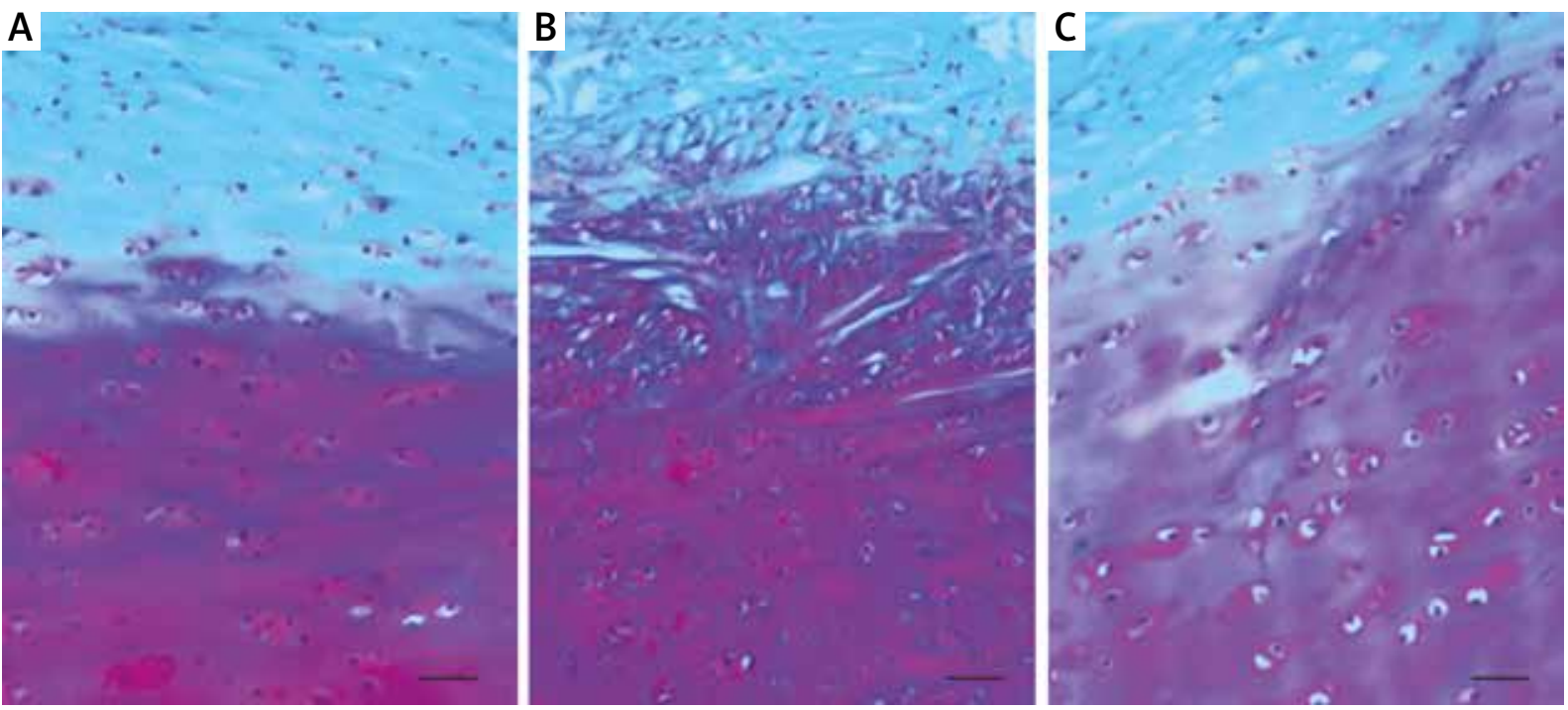

Fig. 4. A) Safranin O stained sections - control: Safranin O staining is based on the binding of a cationic dye to the anionic groups of mucopolysaccharides of the cartilage. Normal structural organisation and uniform Safranin O staining. In the intact discs, the inner annulus and part of the outer annulus showed similar, strong Safranin O staining, as opposed to the superficial annulus, characterised by a lack of GAGs. They are visible cells with a large central vacuole, indicative of good tissue hydration, and cell nucleus the cell nucleus at the periphery of the cell. B) Morphological changes in degenerated discs: visible organisational disorders at the border of the outer and superficial annulus fibrosus characteristic of the degenerative process induced degeneration produced a disruption to the superficial layer with fissures and loss of chondrocytes and cationic stain depletion of the upper two third of the cartilage in the deep zone. C) Changes after mesenchymal stem cells transplantation: increase of cationic staining in the deep zone of the annulus fibrosus, normal, large vacuolated cells. Scale bar represents $200 \mu \mathrm{m}$.

Those results proved that MSCs are able to survive and proliferate after implantation into the IVD.

Serigano et al. [44] demonstrated that the number of cells transplanted affects the regenerative capability of MSC transplants in experimentally induced degenerated canine discs. The optimal BM-MSC injection dose to maintain survival and localisation of BM-MSCs within the central NP region was a dose of $10^{5}$ and $10^{7}$ cells/disc, but $10^{6}$ cells/disc showed the least apoptosis with similar regenerative efficacy compared with a higher injection dose. Similar results for disc regeneration were achieved when adopting a lower dose $\left(0.5 \times 10^{6}\right.$ cells/disc) compared with the higher dose ( $4 \times 10^{6}$ cells/disc), but the lower dose showed superior cell survival [17]. This supports the finding of Serigano et al. [44] that the avascular IVD has a defective nutrient supply that may suppress the survival of MSCs when excess cells are injected $[17,44,45]$. We, therefore believe that the dose we chose is optimal for cell survival, and that the observed regeneration process may be a result of MSC differentiation toward NP cells or their paracrine effect.

However, the success of stem cell-based therapy for the treatment of intervertebral disc degeneration (IVDD) depends on the efficient delivery of transplanted cells, long-term retention within damaged tissue, appropriate differentiation, and the production of an extracellular matrix. The transplanted cells deposit new matrix proteins, enabling the disc to recover its function [20]. Vadala et al. demonstrated that MSCs in suspension tend to leak into the surrounding disc, which leads to osteophyte formation. Histological analysis of intervertebral discs after MSC transplantation showed the presence of the osteophytes, which were composed of mineralised tissue surrounded by chondrocytes, with the labelled MSCs among the osteophyte-forming cells. The presence of MSCs in the osteophytes suggests a potential side effect with this approach [50]. The use of scaffolds in the transplantation of MSCs diminishes the risk of 
cell leakage, which is critical for clinical application $[32,34,47]$.

The method of cell delivery used in the present study was based on the introduction of MSCs suspended in hydrogel. BM-MSCs and hydrogel were administered to the damaged disc under fluoroscopic guidance. Moreover, an injectable hydrogel, acting as a reservoir for cell delivery and mimicking the native environment, provides a framework for MSC growth and differentiation, and offers promise for NP repair and regeneration [12]. Bendtsen et al. [6] showed that MSCs suspended in hydrogel were able to maintain blood flow, volume, and the permeability of vertebral endplates and subchondral bone for a period of three months.

The few in vivo studies have shown promise in retaining disc height and MRI T2 signal intensity, which is the gold standard in determining disc health $[36,37]$. MSCs transplanted into degenerative discs in rabbits proliferated and differentiated into cells expressing some of the major phenotypic characteristics of nucleus pulposus cells, suggesting that these MSCs may have undergone site-dependent differentiation. At MRI imaging, degenerating IVDs treated with MSCs showed improvement compared to controls, both in IVD height and hydration [42]. Disc height and signal intensity have been used as indicators of disc degeneration. Modic et al. [31] reported that the signal loss in the disc on T2-weighted MRI scans correlated with the progressive degenerative changes in the IVD. A high signal intensity on T2-weighted images on MRI is often used to evaluate water content in the IVD $[9,30]$. We observed that the signal loss in the damaged disc was less pronounced in the group of IVDs after MSCs transplantation. To display the correlation between tissue alterations and disc degeneration repair observed in MRI, histological staining was performed as a method of validation.

\section{Conclusions}

A delivery of BM-MSCs into degenerative discs leads to a slowdown in the degeneration process. These results showed that PLDD, as well as cell transplantation, can be performed at the same time, thus facilitating the application of cell therapy and avoiding extended treatment. Our results show that autologous MSC transplantation is both feasible and safe, with no major adverse effects recorded.

\section{Acknowledgments}

This work was sponsored by the National Science Centre (NCN), grant numbers 2012/07/B/NZ4/01427 and 2012/05/D/NZ3/02028.

\section{Disclosure}

The authors report no conflict of interest.

\section{References}

1. Acosta FL, Metz L, Adkisson HD, Liu J, Carruthers-Liebenberg E, Milliman C, Maloney M, Lotz JC. Porcine intervertebral disC repair using allogenic juvenile articular chondrocytes or mesenchymal stem cells. Tissue Eng Part A 2011; 17: 3045-3055.

2. Alini M, Eisenstein SM, Ito K, Little C, Kettler AA, Masuda K, Melrose J, Ralphs J, Stokes I, Wilke HJ. Are animal models useful for studying human disc disorders/degeneration? Eur Spine J 2008; 17: 2-19.

3. An HS, Takegami K, Kamada H, Nguyen CM, Thonar EJ, Singh K, Andersson GB, Masuda K. Intradiscal administration of osteogenic protein-1 increases intervertebral disc height and proteoglycan content in the nucleus pulposus in normal adolescent rabbits. Spine (Phila Pa 1976) 2005; 30: 25-31.

4. Andersson G. Epidemiological features of chronic low back pain. Lancet 1999; 354: 581-585.

5. Barczewska M, Wojtkiewicz J, Habich A, Janowski M, Adamiak Z, Holak P, Matyjasik H, Bulte JW, Maksymowicz W, Walczak. MR monitoring of minimally invasive delivery of mesenchymal stem cells into the porcine intervertebral disc. PLoS One 2013; 8: e74658.

6. Bendtsen M, Bünger CE, Zou X, Foldager C, Jørgensen HS. Autologous stem cell therapy maintains vertebral blood flow and contrast diffusion through the endplate in experimental intervertebral disc degeneration. Spine (Phila Pa 1976) 2011; 36: E373-E379.

7. Brisby $H$. Pathology and possible mechanisms of nervous system response to disc degeneration. J Bone Joint Surg Am 2006; 88 Suppl 2: 68-71.

8. Buckwalter JA. Aging and degeneration of the human intervertebral disc. Spine (Phila Pa 1976) 1995; 20: 1307-1314.

9. Cai F, Wu XT, Xie XH, Wang F, Hong X, Zhuang SY, Zhu L, Rui YF, Shi R. Evaluation of intervertebral disc regeneration with implantation of bone marrow mesenchymal stem cells (BMSCs) using quantitative T2 mapping: a study in rabbits. Int Orthop 2015; 39: 149-159.

10. Chen WH, Liu HY, Lo WC, Wu SC, Chi CH, Chang HY, Hsiao SH, Wu CH, Chiu WT, Chen BJ, Deng WP. Intervertebraldisc regeneration in an ex vivo culture system using mesenchymal stem cells and platelet-rich plasma. Biomaterials 2009; 30: 5523-5533.

11. Clouet J, Pot-Vaucel M, Grimandi G, Masson M, Lesoeur J, Fellah BH, Gauthier O, Fusellier M, Cherel Y, Maugars Y, Guicheux J, Vinatier $C$. Characterization of the age-dependent intervertebral disc changes in rabbit by correlation between MRI, histology and gene expression. BMC Musculoskelet Disord 2011; $12: 147$. 
12. Collin EC, Grad S, Zeugolis DI, Vinatier CS, Clouet JR, Guicheux JJ, Weiss P, Alini M, Pandit AS. An injectable vehicle for nucleus pulposus cell-based therapy. Biomaterials 2001; 32: 2862-2870.

13. Crevensten G, Walsh AJ, Ananthakrishnan D, Page P, Wahba GM, Lotz JC, Berven S. Intervertebral disc cell therapy for regeneration: mesenchymal stem cell implantation in rat intervertebral discs. Ann Biomed Eng 2004; 32: 430-434.

14. Feng G, Zhao X, Liu H, Zhang H, Chen X, Shi R, Liu X, Zhao X, Zhang W, Wang B. Transplantation of mesenchymal stem cells and nucleus pulposus cells in a degenerative disc model in rabbits: a comparison of 2 cell types as potential candidates for disc regeneration. J Neurosurg Spine 2011; 14: 322-329.

15. Gimble JM, Guilak F. Adipose-derived adult stem cells: isolation, characterization, and differentiation potential. Cytotherapy 2003; 5: 362-369.

16. Gimble JM, Katz AJ, Bunnell BA. Adipose-derived stem cells for regenerative medicine. Circ Res 2007; 100: 1249-1260.

17. Ghosh P, Moore R, Vernon-Roberts B, Goldschlager T, Pascoe D, Zannettino A, Gronthos S, Itescu S. Immunoselected STRO-3+ mesenchymal precursor cells and restoration of the extracellular matrix of degenerate intervertebral discs. J Neurosurg Spine 2012; 16: 479-488.

18. Gorensek M, Joksimovic C, Kregar-Velikonja N Gorensek M, Knezevic M, Jeras M, Pavlovcic V, Cör A. Nucleus pulposus repair with cultured autologous elastic cartilage derived chondrocytes. Cell Mol Biol Lett 2004; 9:363-373.

19. Grisendi G, Annerén C, Cafarelli L, Sternieri R, Veronesi E, Cervo GL, Luminari S, Maur M, Frassoldati A, Palazzi G, Otsuru S, Bambi F, Paolucci P, Pierfranco C, Horwitz E, Dominici M. GMP-manufactured density gradient media for optimized mesenchymal stromal/stem cell isolation and expansion. Cytotherapy 2010; 12: 466-477.

20. Guter CC, See EY, Blanquer SB, Pandit A, Ferguson SJ, Benneker LM, Grijpma DW, Sakai D, Eglin D, Alini M, Iatridis JC, Grad S. Challenges and strategies in the repair of ruptured annulus fibrosus. Eur Cell Mater 2013; 2: 1-21.

21. Hiyama A, Mochida J, Iwashina T, Omi H, Watanabe T, Serigano K, Tamura F, Sakai D. Transplantation of mesenchymal stem cells in a canine disc degeneration model. J Orthop Res 2008; 26: 589-600.

22. Henriksson HB, Svanvik T, Jonsson M, Hagman M, Horn M, Lindahl A, Brisby H. Transplantation of human mesenchymal stems cells into intervertebral discs in a xenogeneic porcine model. Spine (Phila Pa 1976) 2009; 34: 141-148.

23. Ho G, Leung VYL, Cheung KMC, Chan D. Effect of severity of intervertebral disc injury on mesenchymal stem cell-based regeneration. Connect Tissue Res 2008; 49: 15-21.

24. Hohaus C, Ganey TM, Minkus Y, Meisel HJ. Cell transplantation in lumbar spine disc degeneration disease. Eur Spine J 2008; 17: 492-503.

25. Jezierska-Wozniak K, Barczewska M, Habich A, Wojtacha P, Badowska W, Maksymowicz W, Wojtkiewicz J. The feasibility of the CD271+ and CD271- mesenchymal stromal cell enrichment toward nucleus pulposus-like cells. Folia Histochem Cytobio 2017; 55: 114-123.

26. Leung VYL, Chan D, Cheung KMC. Regeneration of intervertebral disc by mesenchymal stem cells: potentials, limitations, and future direction. Eur Spine J 2006; 15 Suppl 3: S406-S413.
27. Lilliefors HW. On the Kolmogorov-Smirnov test for normality with mean and variance unknown. J Am Stat Assoc 1967; 62: 399-402.

28. Lipiński S, Jezierska-Woźniak K, Habich A, Barczewska M, Wojtkiewicz J, Walczak P, Maksymowicz W. Methodology for Assessing the Degree of Degeneration of the Porcine Intervertebral Discs Based on Magnetic Resonance Imaging. IFMBE Proceedings 2016; 53: 399-402.

29. Lotz JC. Animal models of intervertebral disc degeneration: lessons learned. Spine (Phila Pa 1976) 2004; 29: 2742-2750.

30. Luoma K, Vehmas T, Riihimäki H, Raininko R. Disc height and signal intensity of the nucleus pulposus on magnetic resonance imaging as indicators of lumbar disc degeneration. Spine (Phila Pa 1976) 2001; 26: 680-686.

31. Modic MT, Masaryk TJ, Ross JS, Carter JR. Imaging of degenerative disk disease. Radiology 2001; 168: 177-186.

32. Nishimura K, Mochida J. Percutaneous reinsertion of the nucleus pulposus: an experimental study. Spine (Phila Pa 1976) 1998; 23: 1531-1538.

33. Nomura T, Mochida J, Okuma M, Nishimura K, Sakabe K. Nucleus pulposus allograft retards intervertebral disc degeneration. Clin Orthop Relat Res 2001; 389: 94-101.

34. Oehme D, Ghosh P, Shimmon S, Wu J, McDonald C, Troupis JM, Goldschlager T, Rosenfeld JV, Jenkin G. Mesenchymal progenitor cells combined with pentosan polysulfate mediating disc regeneration at the time of microdiscectomy: a preliminary study in an ovine model. J Neurosurg Spine 2014; 20: 657-669

35. Orozco L, Soler R, Morera C, Alberca M, Sánchez A, García-Sancho J. Intervertebral disc repair by autologous mesenchymal bone marrow cells: a pilot study. Transplantation 2001; 92: 822-828.

36. Osti OL, Vernon-Roberts B, Moore R, Fraser RD. Annular tears and disc degeneration in the lumbar spine. A post mortem study of 135 discs. J Bone Joint Surg 1992; 74: 678-882.

37. Pfirrmann CW, Metzdorf A, Elfering A, Hodler J, Boos N. Effect of aging and degeneration on disc volume and shape: a quantitative study in asymptomatic volunteers. J Orthop Res 2006; 24: 1086-1094.

38. Richardson SM, Walker RV, Parker S, Rhodes NP, Hunt JA, Freemont AJ, Hoyland JA. Intervertebral disc cell-mediated mesenchymal stem cell differentiation. Stem Cells 2006; 24: 707-716.

39. Risbud MV, Albert TJ, Guttapalli A, Vresilovic EJ, Hillibrand AS, Vaccaro AR, Shapiro IM. Differentiation of mesenchymal stem cells towards a nucleus pulposus-like phenotype in vitro: implications for cell-based transplantation therapy. Spine (Phila Pa 1976) 2004; 29: 2627-2632.

40. Rosenberg LJ. Chemical basis for the histological use of safranin $O$ in the study of articular cartilage. Bone Joint Surg Am 1971; 53: 69-82.

41. Roberts S, Eisenstein SM, Menage J, Evans EH, Ashton IK. Mechanoreceptors in intervertebral discs. Morphology, distribution, and neuropeptides. Spine (Phila Pa 1976) 1995; 20: 2645-2651.

42. Sakai D, Mochida J, Iwashina T, Watanabe T, Nakai T, Ando K, Hotta T. Differentiation of mesenchymal stem cells transplanted to a rabbit degenerative disc model: potential and limitations for stem cell therapy in disc regeneration. Spine (Phila Pa 1976) 2005; 30: 2379-2387. 
43. Sakai D, Mochida J, Iwashina T, Hiyama A, Omi H, Imai M, Nakai T, Ando K, Hotta T. Regenerative effects of transplanting mesenchymal stem cells embedded in atelocollagen to the degenerated intervertebral disc. Biomaterials 2006: 27: 335-345.

44. Serigano K, Sakai D, Hiyama A, Tamura F, Tanaka M, Mochida J. Effect of cell number on mesenchymal stem cell transplantation in a canine disc degeneration model. J Orthop Res 2010; 28: 1267-1275.

45. Sobajima S, Vadala G, Shimer A, Kim JS, Gilbertson LG, Kang JD, Feasibility of a stem cell therapy for intervertebral disc degeneration. Spine J 2008; 8: 888-896.

46. Steck E, Bertram H, Abel R, Chen B, Winter A, Richter W. Induction of intervertebral disc-like cells from adult mesenchymal stem cells. Stem Cells 2005; 23: 403-411.

47. Subhan RA, Puvanan K, Murali MR, Raghavendran HR, Shani S, Abdullah BJ, Abbas AA, Mohamed JA, Kamarul T. Fluoroscopy assisted minimally invasive transplantation of allogenic mesenchymal stromal cells embedded in HyStem reduces the progression of nucleus pulposus degeneration in the damaged interverbal disc: a preliminary study in rabbits. Sci World J 2014; 2014: 818502.

48. Thompson JP, Oegema TR, Bradford DS. Stimulation of mature canine intervertebral disc by growth factors. Spine (Phila Pa 1976) 1991; 16: 253-260.

49. Walsh AJL, Bradford DS, Lotz JC. In Vivo growth factor treatment of degenerated intervertebral discs. Spine (Phila Pa 1976) 2004; 29: 156-163.

50. Vadala G, Studer RK, Sowa G, Spiezia F, lucu C, Denaro V, Gilbertson LG, Kang JD. Coculture of bone marrow mesenchymal stem cells and nucleus pulposus cells modulate gene expression profile without cell fusion. Spine (Phila Pa 1976) 2008; 33: 870-876.

51. Yamamoto Y, Mochida J, Sakai D, Nakai T, Nishimura K, Kawada H, Hotta T. Upregulation of the viability of nucleus pulposus cells by bone marrowderived stromal cells: significance of direct cell-to-cell contact in co-culture system. Spine (Phila Pa 1976) 2004; 29: 1508-1514.

52. Yang X, Li X. Nucleus pulposus tissue engineering: a brief review. Eur Spine J 2009; 18: 1564-1572.

53. Yang F, Leung VYL, Luk KDK, Chan D, Cheung KMC. Mesenchymal stem cells arrest intervertebral disc degeneration through chondrocytic differentiation and stimulation of endogenous cells. Mol Ther 2009; 17: 1959-1966.

54. Yoshikawa T, Ueda Y, Miyazaki K, Koizumi M, Takakura Y. Disc regeneration therapy using marrow mesenchymal cell trans plantation: a report of two case studies. Spine (Phila Pa 1976) 2010; 35: E475-E480.

55. Zhang Y, Drapeau S, Howard SA, Thonar EJ, Anderson DG. Transplantation of goat bone marrow stromal cells to the degenerating intervertebral disc in a goat disc injury model. Spine (Phila Pa 1976) 2011; 36: 372-377. 